\title{
EVALUATING OF A PROTOTYPE MACHINE FOR CARROT CROP HARVESTING SUITABLE FOR SMALL HOLDINGS
}

\author{
Ahmed M. Oda*, M.K. Abd El-Wahab, M.A. Tawfik and K.I. Wasfy \\ Agric. Eng. Dept., Fac. Agric., Zagazig Univ., Egypt
}

Received: 20/11/2017 ; Accepted: 03/12/2017

\begin{abstract}
The aim of this paper is evaluating the performance of prototype carrot harvester recorded, as patent that specialized in carrot crop harvesting using lifting belts technique. Two groups of practical experiments were performed to evaluate the prototype machine. The first one is the preliminary experiments to find out the maximum length of the cultivated carrot variety to determine the optimum digging depth in addition to the optimum moisture contents of soil and foliage as well as the catch zone height. The second one is the main experiment that aims to evaluate the performance of the harvester under four forward speeds $(1,2,3$ and $4 \mathrm{~km} / \mathrm{hr}$.), four lifting- belt speeds $(1,2,3$ and 4 $\mathrm{m} / \mathrm{sec}$.); three belt tilt angles $\left(30^{\circ}, 35^{\circ}\right.$ and $\left.40^{\circ}\right)$ and three rake angles share of the digging share $\left(15^{\circ}\right.$, $20^{\circ}, 25^{\circ}$ ) with taking into consideration the performance indicator that including the field capacity, field efficiency, harvesting losses, lifting efficiency, specific energy requirement and total harvesting cost compared to the manual harvesting. According to the preliminary experiments, the prototype carrot harvester should be used under soil and foliage moisture content of 17.7 and $27.8 \%$, respectively at catch zone height of $15 \mathrm{~cm}$ and digging depth of $25 \mathrm{~cm}$. Regarding the field experiment, the operation of carrot harvester using forward speed of $2 \mathrm{~km} / \mathrm{hr}$., belt speed of $2 \mathrm{~m} / \mathrm{sec}$., in other word the kinematic factor of 3.57 under belt tilt angle of $30^{\circ}$ and share rake angle of $15^{\circ}$ achieved the lowest losses of $0.18 \mathrm{Mg} /$ fad., highest lifting efficiency of $98.54 \%$, field efficiency of $92.50 \%$ with minimum total cost of $424.32 \mathrm{LE} / \mathrm{fad}$., at actual field capacity of $0.0148 \mathrm{fad} / \mathrm{hr}$. Ultimately, using of the carrot harvester reduced the harvesting cost with about $80.74 \%$ compared to the manual harvesting method.
\end{abstract}

Key words: Small holdings, prototype, mechanical harvesting, carrot harvester, catch zone height, kinematic factor

\section{INTRODUCTION}

Carrot (Daucus carota) crop is considered as a mine of vitamins, minerals and fibers that keep human healthy, the world production of carrot reached to 37.2 million tons according to FAO (2013), but in Egypt the total cultivated area is about 5000 HA (hectare) with an annually production of 143,000 tons FAO (2013). In Egypt, the problem of small holdings is the biggest barrier to exploit the farm machinery in the agricultural mechanization processes, especially the large-scale machines for most of field crops or even vegetables. From the economical aspect, the agricultural machinery is using successfully in large holdings and

\footnotetext{
* Corresponding author: Tel. : +201090150083

E-mail address: aoda79@yahoo.com
}

therefore the concept of using the bulk farm machinery in small areas is very difficult to implement. Unfortunately, there is no specialized machine for harvesting the carrot crop in Egypt, whereas the exported harvesting combines are generally massive, expensive and insufficient in their energy utilization in the small cultivated areas. Harvesting is a critical operation for the crop production because the improper harvesting techniques affecting bruising and consequently storing, marketing and trading processes (Tawfik and Abdallah, 2012). Nowadays, the carrot crop harvesting operation in Egypt is performing whether manually by using the nails or mechanically by chisel plow and the potato digger. Despite the 
manual method gives the minimum losses that represents in the peeled, scuffad, bruised or even un-lifted roots compared to the other conventional mechanical methods, but it needs a lot of labors, time and cost. Nevertheless, the chisel plow and potato digger are the most widespread equipment used to harvest the carrot crop. Moukhtar (1997) compared between different methods for carrot harvesting under the Egyptian conditions involving; chisel plow, potato digger and manual method after cultivation using pneumatic planter. $\mathrm{He}$ mentioned that, the potato digger gave the lowest losses of 0.55 ton/fad., but the power consumption of $103.65 \mathrm{~kW} /$ fad., relatively still high. Simultaneously, the chisel plow shares caused severe damage to the roots and consequently the losses increased. Recently, limited attempts to improve the carrot harvesting technique by using developed or adapted potato harvesters (diggers). Shirwal et al. (2014) developed a potato harvesting machine to harvest carrot crop using digging blade and separating unit by studying some factors affecting the machine performance. The results indicated that the optimum parameter for the unit were $60 \mathrm{~cm}$ length of soil separator, $25^{\circ}$ of rake angle and $20^{\circ}$ of soil separator angle at forward speed of $2.3 \mathrm{~km} / \mathrm{hr}$., to achieve the highest lifting efficiency of $97.18 \%$ and carrot root damage of 4.6\%. Amin et al. (2014) modified a potato digger to harvest carrot crop. The digger performance was investigated under different levels of separator length; reciprocated cam with link length, forward speeds and blade shape types (Sweeping, Nose and Shovel). The obtained results revealed that the maximum value of carrot lifting efficiency of $99 \%$ and the minimum damaged roots of $2 \%$ recorded at forward speed $3.6 \mathrm{~km} / \mathrm{hr}$., separator length of $1200 \mathrm{~mm}$ and reciprocated cam with link length of $210 \mathrm{~mm}$ using the nose shape type. The main drawback of using the modified potato digger to harvest carrot crop is the high energy consumption and the rise of harvesting costs due to manual collecting. According the previous literatures, there is an urgent need to harvest the carrot crop by a delicate harvesting machine to achieve the minimum crop losses, energy consumption and cost provided with a collecting bunker to avoid the manual collecting. Hence, this paper aims to investigate the performance of a prototype single row specialized carrot harvesting machine using lifting-belts technique suitable for small holdings. This machine was recorded as patent (Oda1- 998/2017) with copyright referred to (MA Tawfik, MK Kadry and AM Oda).

\section{MATERIALS AND METHODS}

The practical experiments of this work were carried out during two agricultural seasons of 2015-2016/ 2016-2017 at a private farm in Abou Hammad District, Sharkia Governorate, Egypt. The overall area of the experimental site was about 1.5 fad., $(20.3 \mathrm{~m} \mathrm{Wx} 310 \mathrm{ml})$ which is divided into two plots. The first one was exploited to evaluate the performance of prototype carrot harvester with total area of about 1.36 fad $(310 \mathrm{x} 18.5 \mathrm{~m})$ including the surrounding turn-strips, where the area of every treatment was $30 \mathrm{~m}^{2}(100 \times 0.3 \mathrm{~m})$. The second plot was dedicated for the manual harvesting using nails with total area of about 0.14 fad $(1.8 \times 310 \mathrm{~m})$. The carrot crop was cultivated mechanically using the pneumatic planter.

The soil mechanical analysis of experimental site was performed at depth of $0-30 \mathrm{~cm}$ using the hydrometer method at the Laboratory of Soil Sciences Department, Fac. Agric., Zagazig Univ. The soil was classified as a sandy-loam soil as demonstrated in Table 1.

\section{Materials}

\section{Carrot variety}

The variety of carrots used in this experiment is the Hybrid Fire Wedge- F1 produced by TAKI Company, Japan.

\section{Tractors}

Two types of four-wheel tractors were used, the first one is John deer 5080R (80 hp, 59.7 $\mathrm{kW}$ ) that used with the pneumatic planter, while the second is Kubota L2402-DT (28 hp, 20.59 $\mathrm{kW})$ used with the prototype harvester.

\section{Mechanical planting}

The pneumatic planter (AGRIMIR VPS-6) with working width of $180 \mathrm{~cm}$ was used for cultivating the carrot seeds. 
Table 1. Soil mechanical analysis

\begin{tabular}{cccccc}
\hline Soil depth (cm) & Clay (\%) & Silt (\%) & Fine sand (\%) & Coarse sand (\%) & Soil classification \\
\hline $0-30$ & 28.9 & 16.2 & 41.5 & 13.4 & Sandy loam \\
\hline
\end{tabular}

\section{Carrot harvester}

The patented prototype carrot harvester is using the lifting-belts technique with cleavage digging share for the picking-up carrot root from the soil by catching the foliage, then transferring the lifting root to the bunker, as depicted in Figs. 1 and 2. Basically, the harvester consists of the following main parts:

\section{The main chassis}

The main chassis is a metal frame with 200 $\mathrm{cm}$ in length and $50 \mathrm{~cm}$ in width, which carried on two wheels. The chassis is carrying the collecting bunker, mounting tower involving three hatching point to mount the machine beside the tractor and the main shaft, which take the motion from the tractor PTO by a universal joint.

\section{Lifting unit holder}

The holder is the link between the main chassis, lifting belt unit and digging share, in addition to it was connected with a hydraulic cylinder to the machine to control the operation of the lifting unit and digging share.

\section{Digging share}

The digging share is similar to the chisel plow share with length $20 \mathrm{~cm}$ and $2 \mathrm{~cm}$ in width. The main function of the share is for cleaving and dismantling of the soil section beneath the carrot root to facilitate the lifting process.

\section{Lifting unit}

The lifting unit consists of inclined pair of belts opposite each other provided with tightened pulleys to press the two belts towards each other. The main function of the lifting unit is to catch and lift the roots and drop them off in the bunker.

\section{Transmission system}

The power transmitted from the tractor PTO to the lifting belts by means of pulleys, chains and gearbox. The transmission system designed to give the lifting belts four different speeds based on PTO speed of $850 \mathrm{rpm}$.

\section{Methods}

\section{Treatments}

The field experiments were carried out through two treatments as follow:

- Pneumatic planter + mechanical harvesting.

- Pneumatic planter + manual harvesting.

The preparation of the experimental soil was chiseled two times, leveled by laser leveler and the other mechanization processes such as irrigation and crop service were conducted in all treatments according to the technical recommendations.

\section{Planting method}

The carrot seeds was sown mechanically at raw spacing of $30 \mathrm{~cm}$, spacing between plants $10 \mathrm{~cm}$ in raw and depth of $3 \mathrm{~cm}$, using average forward speed of $3.5 \mathrm{~km} / \mathrm{hr}$.

\section{Harvesting methods}

The manual harvesting method was performed by using the nails, while the proto type machine was used in mechanical harvesting, the prototype carrot harvester moved within the field according to the pattern of circuitous paths from outside to inside the field as using the field surrounding turn-strips.

The performance investigation of the prototype carrot harvester was conducted through two experiments as follow:

\section{The preliminary experiments}

The preliminary experiments were performed to study the physical properties of the carrot root including the root length to determine the proper digging share depth. Likewise, these experiments are aiming to optimize the soil, foliage and root moisture contents as well as the 

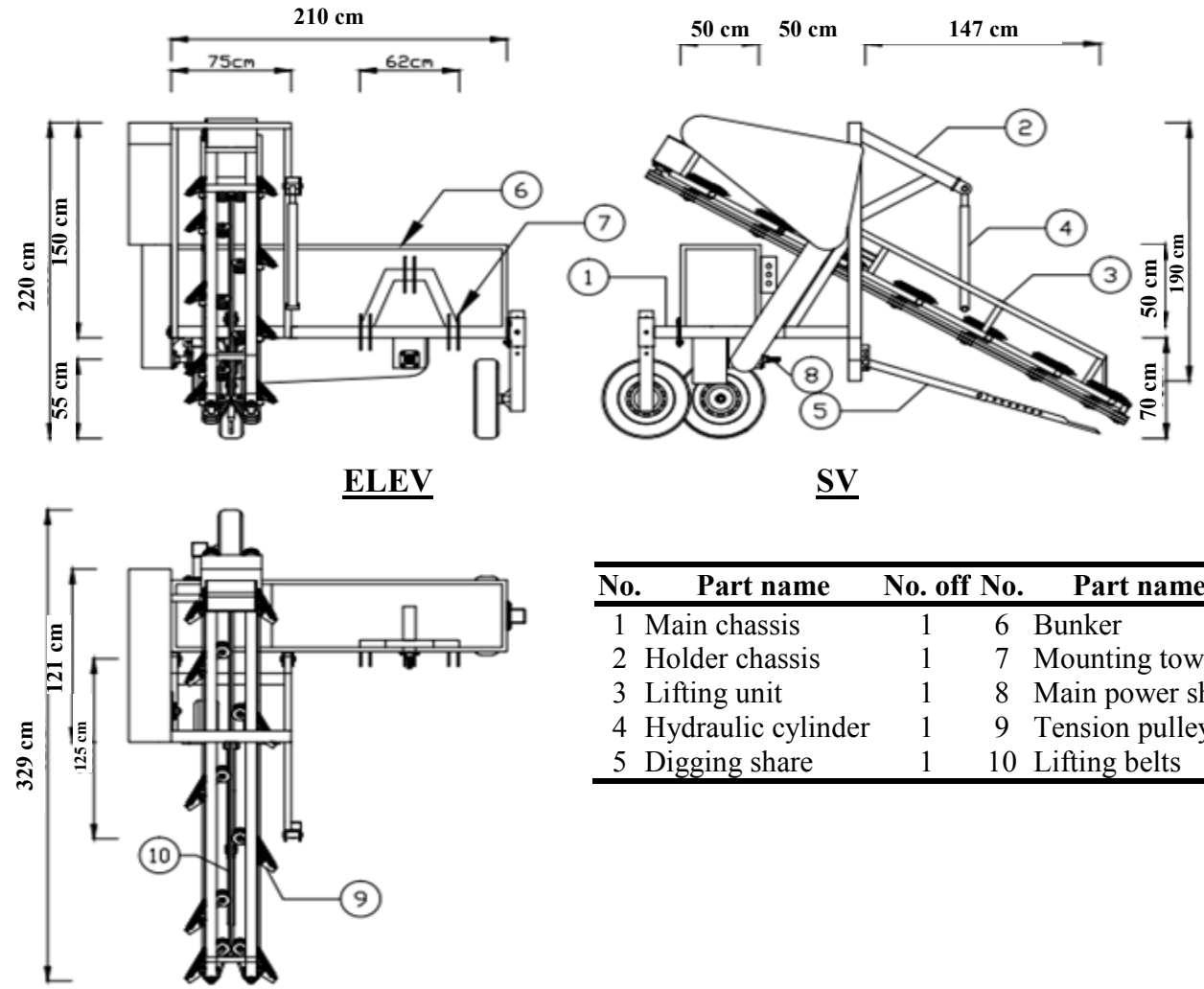

$\underline{\text { PLAN }}$

Fig. 1. Elevation, plan and side view of the carrot harvester

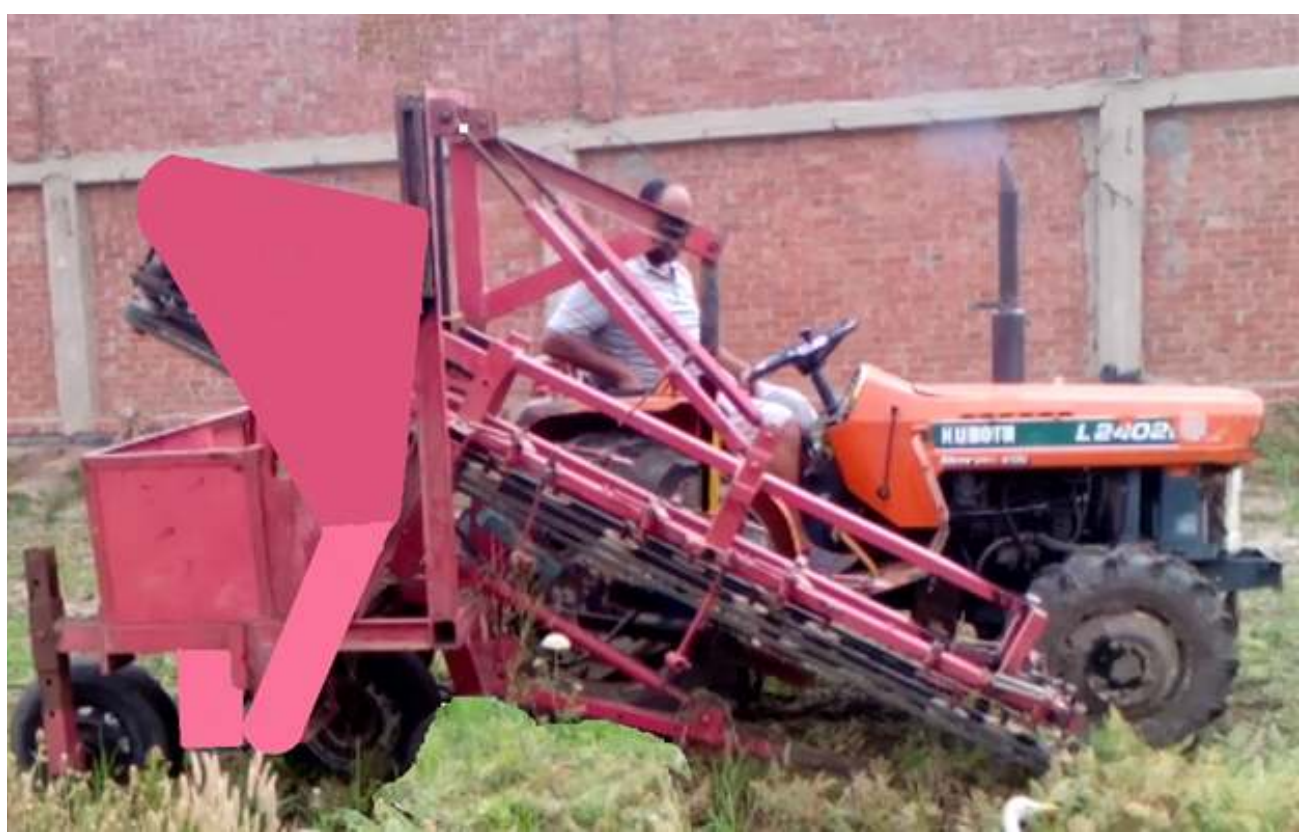

Fig. 2. Pictorial view of the carrot harvester 
catch zone height that achieved the minimum required tension force of lifting the plant through the following parameters:

1. Three different soil (17.7, 15.5 and $13.5 \%)$ and foliage (27.8, 18.7 and 17.2\%) moisture contents.

2. Two catch zone heights (10 and $15 \mathrm{~cm})$

\section{The main experiments}

The main experiments were performed to optimize the parameters affecting the performance of the prototype carrot harvester, these parameters are:

1. Four forward speeds of $1,2,3$ and $4 \mathrm{~km} / \mathrm{hr}$.

2. Four lifting belt speeds of 1,2 , 3and $4 \mathrm{~m} / \mathrm{sec}$.

3. Three lifting belts tilt angle of $30^{\circ}, 35^{\circ}$ and $40^{\circ}$.

4. Three blade rake angles of $15^{\circ}, 20^{\circ}$ and $25^{\circ}$.

\section{Measurements}

The evaluation of the carrot harvester performance was based on the following indicators:

\section{Field capacity}

The theoretical field capacity was calculated from the following equation :

$$
\mathrm{TFC}=\frac{\mathrm{Fs} \times \mathrm{Ws}}{4.2} \text { (fad./hr.) }
$$

Where:

TFC $=$ Theoretical field capacity of the machine (fad./ hr).

$$
\text { Fs }=\text { Forward speed }(\mathrm{km} / \mathrm{hr}) \text {. }
$$

Ws = The machine working width (m).

The actual field capacity for mechanical harvesting was calculated as follows:

$$
\mathrm{AFC}=\frac{60}{\mathrm{Tu}+\mathrm{Ti}}(\mathrm{fad} . / \mathrm{hr} .)
$$

Where:

$\mathrm{AFC}=$ The actual field capacity of the machine, $\mathrm{fad} / \mathrm{hr}$

$\mathrm{T}_{\mathrm{u}} \quad=$ The utilized time per faddan in minutes.

$\mathrm{T}_{\mathrm{i}}=$ Total lost time per faddan in minutes.
Whreas the actual field capacity for manual harvesting can be calculated by using the following relation:

$$
\mathrm{FC}_{\mathrm{Lab}}=\frac{\mathrm{A}_{\mathrm{L}}}{\mathrm{T}_{\mathrm{c}}} \quad(\mathrm{fad} . / \mathrm{hr} .)
$$

$\mathrm{FC}_{\mathrm{Lab}}=$ Actual field capacity of manual harvesting, fad./hr.

$A_{L}=$ Harvested area (fad.)

$\mathrm{T}_{\mathrm{c}}=$ Total consumed time (hr.)

\section{Field efficiency}

The field efficiency can be estimated by using the following equation:

$$
\eta \mathrm{f}=\frac{\mathrm{AFC}}{\mathrm{TFC}} \times 100(\%)
$$

Where:

$\eta f$ : The field efficiency of the machine (\%).

AFC: The machine actual field capacity (fad./hr.)

TFC: The machine theoretical field capacity (fad./hr.)

\section{Harvesting losses}

Harvesting losses are represented in the unlifted roots, which can be calculated from the following relation :

Harvesting losses $=$

Mass of un-lifted roots in treatment $(\mathrm{kg})$ $\times 100(\%)$

Total mass of treatment $(\mathrm{kg})$

\section{Lifting efficiency}

The harvesting efficiency can be determined as follow:

$$
\begin{aligned}
& \text { Harvesting effciency }(\eta \mathrm{H})= \\
& \frac{\text { mass of lifting roots in sample }(\mathrm{kg})}{\text { mass of the total sample }(\mathrm{kg})} \times 100(\%)
\end{aligned}
$$

\section{Fuel consumption}

Fuel consumption per unit of time was determined by measuring the volume of fuel required to refill the tank after operation time per each treatment by using a graduated cylinder with max. capacity $1000 \mathrm{~cm}^{3}$. It was calculated by using the following relation: 


$$
\mathrm{F}_{\mathrm{c}}=\frac{\mathrm{Vf}}{\mathrm{t}}(1 / \mathrm{hr} .)
$$

Where:

$\mathrm{F}_{\mathrm{c}}=$ Rate of fuel consumption $(1 / \mathrm{hr}$.)

$\mathrm{V}_{\mathrm{f}}=$ Volume of fuel consumed (1)

$\mathrm{T}=$ Time of harvesting (hr.)

\section{Required power}

The harvesting power $\left(\mathrm{P}_{\mathrm{H}}\right)$ was estimated by the following formula (Hunt, 1983):

$$
\mathrm{P}_{\mathrm{H}}=\left[\begin{array}{l}
\mathrm{FC} \times(1 / 3600) \times \mathrm{PE} \times \mathrm{LCV} \times 427 \\
\times \xi_{\mathrm{thb}} \times \xi_{\mathrm{m}} \times 1 / 75 \times 1 / 1.36
\end{array}\right], \mathrm{kW}
$$

Where:

$\mathrm{FC}=$ Fuel consumption, (L/hr.)

$\mathrm{PE}=$ Fuel density (for solar $0.85 \mathrm{~kg} / \mathrm{m}^{3}$ )

$\mathrm{LCV}=$ Calorific value of fuel $(11000 \mathrm{k} . \mathrm{cal} / \mathrm{kg})$

$\xi_{\text {thb }}=$ Thermal efficiency of engine (35\% for diesel engine)

$\xi_{\mathrm{m}}=$ Mechanical efficiency of the engine (85\%)

\section{Energy requirement}

Specific energy requirement can be calculated by using the following equation:

Specific energy requirement $=$

Harvesting power $(\mathrm{kW})$

Actual field capacity (fad./hr.) (kW. hr./fad.)

\section{Cost analysis}

The machine cost was determined using the following formula (Awady et al., 2003):

$\mathrm{C}=\frac{\mathrm{P}}{\mathrm{h}}\left(\frac{1}{\mathrm{E}}+\frac{\mathrm{I}}{2}+\mathrm{T}+\mathrm{R}\right)+(0.9 \mathrm{WSF}) \frac{\mathrm{M}}{144}(\mathrm{LE} / \mathrm{hr}$. $)$

Where:

$\mathrm{C}$ : Machine hourly cost, LE/hr.

$\mathrm{P}$ : Price of the machine, LE/hr.

$\mathrm{h}$ : Yearly working hours.

E : Life expectancy of the machine,year

$\mathrm{I}:$ Interest rate/ year.
Oda, et al.

$\mathrm{T}$ : Taxes, over heads ratio (\%).

$\mathrm{R}$ : Repair and Maintenance ratio (\%).

W : Power, (kW).

$\mathrm{S}$ : specific fuel consumption, (L/kW.hr.).

F : Fuel price, (LE).

M : Operator monthly salary, (LE).

0.9 : Factor accounting for ratio of rated power and lubrications.

144: The monthly average working hours.

The operational cost for mechanical harvesting can be determined as follows:

Operating cost of mechanical harvesting =

(Machine + tractor) hourly cost (LE/hr.)

Actual field capacity (fad./hr.)

The total cost for mechanical harvesting including the machines operating cost and the manual collecting of the un-lifted carrot root as follow:

The total cost of mechanical harvesting (LE/ fad. $)=$ Operational cost of machines (LE/fad. $)+$ manual collecting costs for losses (LE/fad.).

Due to the variation of the amount of carrot root losses in the different treatments, the cost of manual collecting for root losses was estimated on basis of the cost of manual collecting per unit of mass $(\mathrm{kg})$. Through different practical trials, it was found that the average consumed time required to collect mass of loss equal to $22 \mathrm{~kg}$ was about 0.25 -hour (15 min).Thus, the average required time to collect mass unit of carrot by one labor is $0.01 \mathrm{hr} / \mathrm{kg}$.

Hourly cost of one labor $(\mathrm{LE} / \mathrm{hr}$. $)=$

Daily wage of one labor 120

Daily working hours $(8 \mathrm{hr}$.) $=15 \mathrm{LE} / \mathrm{hr}$.

Manual collecting cost per losses mass unit $(\mathrm{LE} / \mathrm{kg})=$ Hourly cost /one labor $(\mathrm{LE} / \mathrm{hr}) \times$ average required time to collect mass unit $(\mathrm{hr} . / \mathrm{kg})=15 \times 0.01=0.15 \mathrm{LE} / \mathrm{kg}$

Manual collecting cost for every treatment $(\mathrm{LE} / \mathrm{fad})=$. mass of losses $(\mathrm{kg} / \mathrm{fad}.) \times 0.15(\mathrm{LE} / \mathrm{kg})$ 


\section{Manual harvesting}

The operational cost for manual lifting and collecting was determined using the following equation:

Operating cost $=$

Harvesting hourly cost (LE/hr.)

Average actual field capacity (fad./hr.)

The manual harvesting treatment area was 30 $\mathrm{m}^{2}$ (one row), which need to one labor at average time 0.82 hour to complete manual lifting in addition to 0.25 hour to accomplish manual collecting.

The average actual field capacity for manual lifting $=(30 / 4200) / 0.82=0.009 \mathrm{fad} . / \mathrm{hr}$.

Operating cost of manual lifting $=(15 / 0.009)=$ 1666.67 LE/fad.

The Actual field capacity for manual collecting $=(30 / 4200) / 0.25=0.028 \mathrm{fad} / \mathrm{hr}$.

Cost of manual collecting $=15 / 0.028=535.7$ LE/fad.

Total cost of manual harvesting was estimated as follows:

The total cost of manual harvesting = Operational cost of manual lifting (LE/fad.) + manual collecting costs (LE/fad.)

The total cost of manual harvesting (lifting+ collecting $)=1666.67+535.7=2202.37 \mathrm{LE} / \mathrm{fad}$.

\section{RESULTS AND DISCUSSION}

The obtained results were discussed under the following topics:

\section{Results of the Preliminary Experiments}

The purpose of the preliminary experiments is to study the physical properties of the used carrot variety in terms to determine the optimum depth of digging share in addition to determining the optimum soil, foliage and root moisture contents, as well as catch zone height that achieve lowest tension force required to lift the root. As shown in Fig. 4, the obtained results showed that the maximum carrot root length was about $19.5 \mathrm{~cm}$; hence, the digging depth must exceed $20 \mathrm{~cm}$ to avoided root damage during harvesting operation. The results of preliminary experiments revealed that, the optimum soil and foliage moisture contents for the lifting of carrot roots were about 17.7 and $27.8 \%$, respectively and catch zone height of $10 \mathrm{~cm}$ which achieved the minimum required tension force of $26.87 \mathrm{~N}$, as illustrated in Fig. 5.

\section{Results of Main Experiments}

\section{Effect of some operational parameters on the machine actual field capacity and field efficiency}

As depicted in Fig. 6-a, the machine actual field capacity increased rapidly by increasing the machine forward speed from 1 to $4 \mathrm{~km} / \mathrm{hr}$., the field efficiency whereas increased by increasing the forward speed from 1 to $2 \mathrm{~km} / \mathrm{hr}$., but any further increase in forward speed the field efficiency tends to decrease rapidly. This because the actual field capacity at high forward speeds is lower than that occurred in the theoretical field capacity. The obtained results showed that, as the forward speed increases from 1 to $4 \mathrm{~km} / \mathrm{hr}$., the machine actual field capacity increased from 0.064 to 0.235 fad./hr., while the field efficiency reached its highest value of $92.5 \%$ at forward speed of $2 \mathrm{~km} / \mathrm{hr}$, share rake angle of $15^{\circ}$, belt speed of $2 \mathrm{~m} / \mathrm{sec}$., and belt tilt angle of $30^{\circ}$. There is no doubt that the relation between the machine forward speed and the lifting belt speed affecting greatly the actual field capacity and field efficiency is the key factor to approach the machine optimum performance. This relation represents in the kinematic factor $(\mathrm{KF})$ resulted by dividing belt speed on forward speed. According to the obtained results, the optimum value of KF was recorded to be 3.57 at forward speed $2 \mathrm{~km} / \mathrm{hr}$. The lower values of KF than the optimum means that, the forward speed is higher than the belt speed, which can lead to excessive load of plant in front of the lifting belt unit and would decrease the actual field capacity and consequently the field efficiency. Nevertheless, the rise of $\mathrm{KF}$ value than the optimum means that the belt speed is higher than the forward speed that made the lifting operation very quick and so that, there is no noticeable change in machine actual field capacity and field efficiency.

Fig. 6-b display that, as the rake angle of digging share increases the actual field capacity and field efficiency decreases due to the increase in the soil resistance. The results showed that, the 


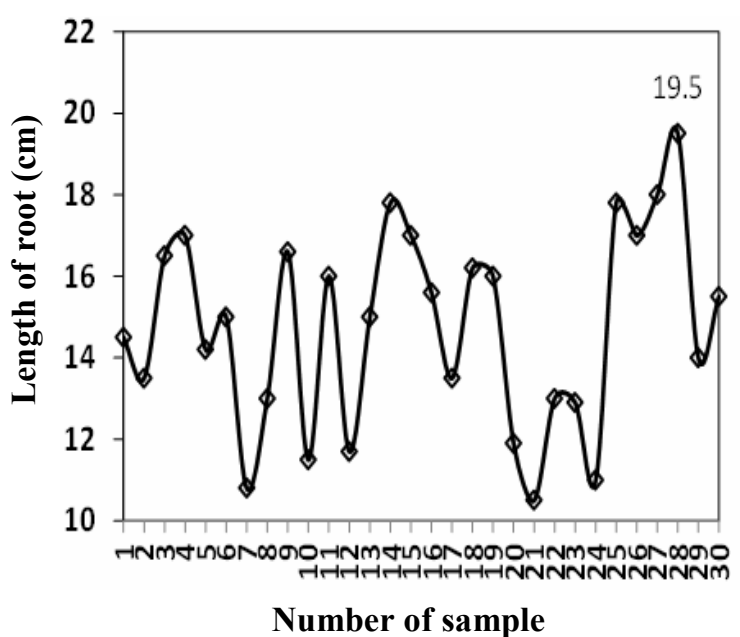

Fig. 4. Roots length of a random 30 samples of carrot plant

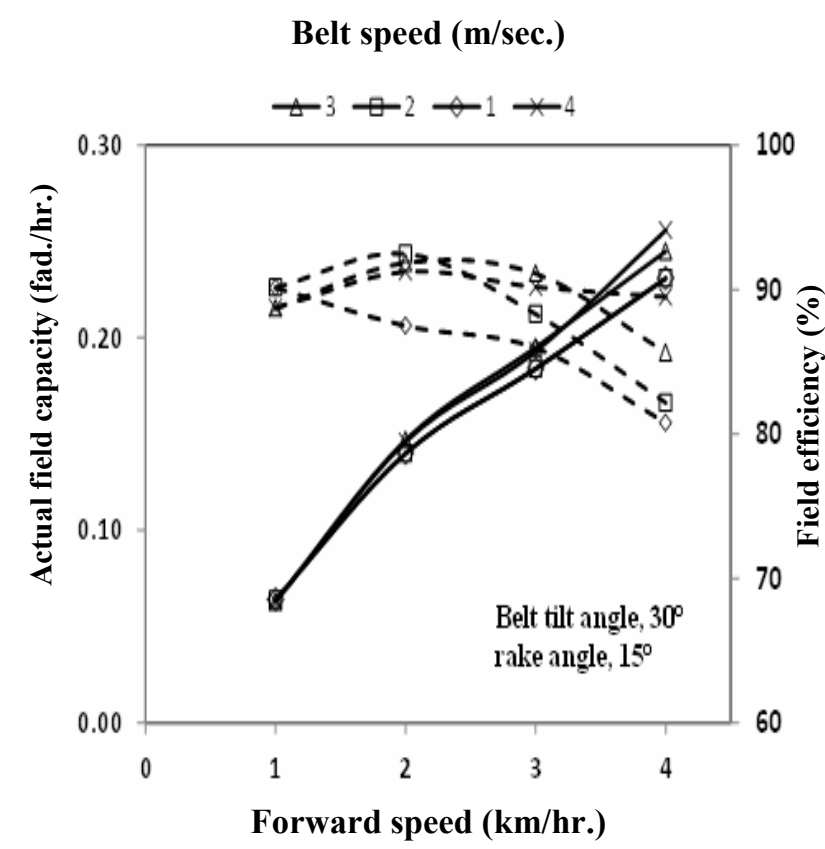

Fig. 6-a. Effect of forward speed and belt speed on actual field capacity and field efficiency

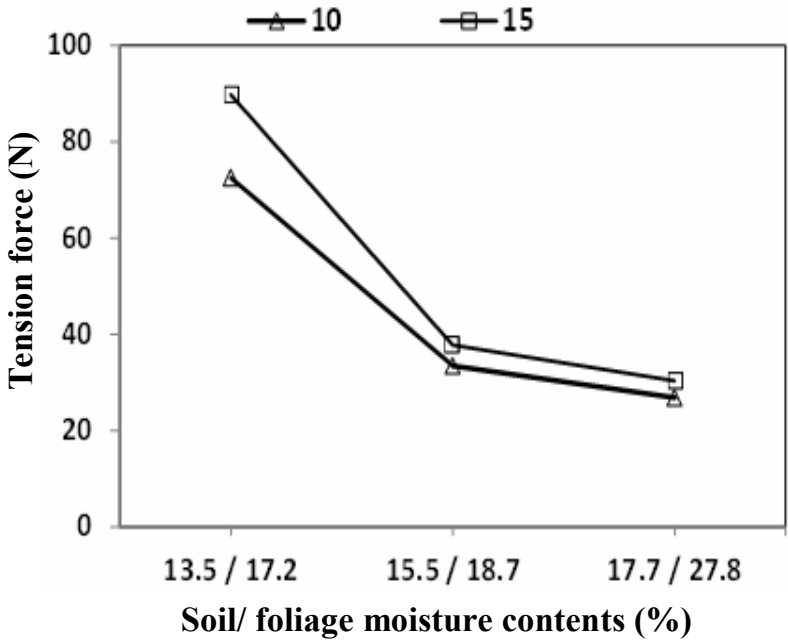

Fig. 5. Tension force under different soil, foliage moisture contents and catch zone heights

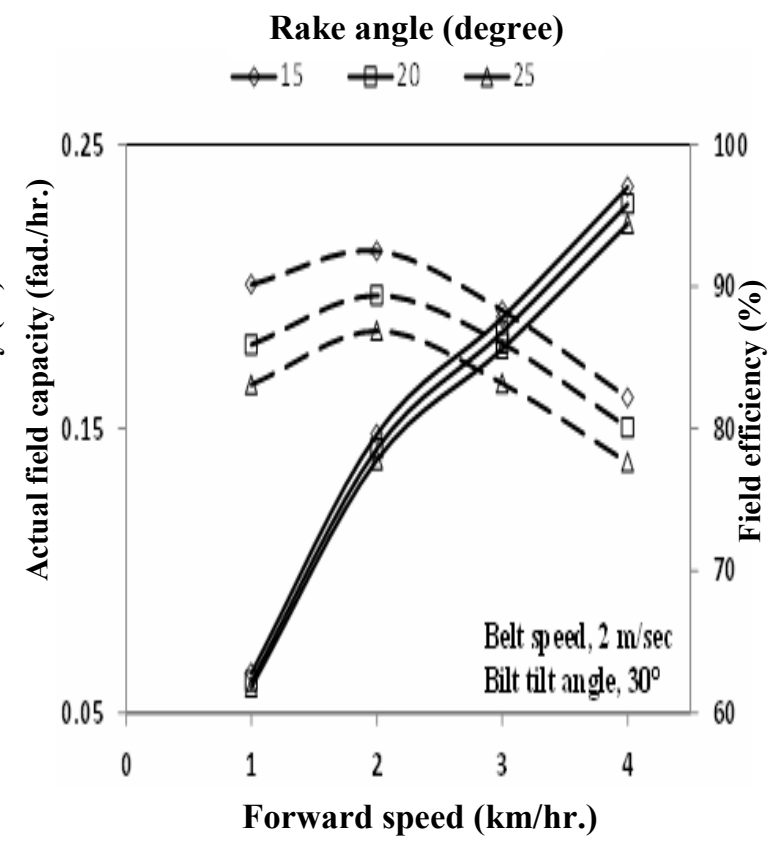

Fig. 6-b. Effect of rake angle on actual field capacity and field efficiency 
increase both of rake angle from $15^{\circ}$ to 25 and forward speed more than $2 \mathrm{~km} / \mathrm{hr}$., led to decrease the actual field capacity from 0.189 to $0.178 \mathrm{fad} . / \mathrm{hr}$., as well as the field efficiency from 88.32 to $83.18 \%$ at belt speed $2 \mathrm{~m} / \mathrm{sec}$., and belt tilt angle $30^{\circ}$.

A forward speed of $2 \mathrm{~km} / \mathrm{hr}$., belt speed 2 $\mathrm{m} / \mathrm{sec}$ and share rake angle $15^{\circ}$, the actual field capacity were $0.148,0.149,0.147 \mathrm{fad} . / \mathrm{hr}$. at belt tilt angle of $30^{\circ}, 35^{\circ}$ and $40^{\circ}$, respectively while the field efficiency were about 92.5, 93.13 and $91.88 \%$ for the same rake angles, respectively, as shown in Fig. 6-c. Hence, there is no significant effect of the lift belt inclination on the actual field capacity and field efficiency under the different forward speeds. This because that the lifting operation depends mainly on the digging blade, as it cuts and dismantling of the soil section beneath the carrot root then the belt unit lifts the root from the soil so the lifting resistance affect mainly the digging blade not the belt unit.

\section{Effect of some operational parameters on the root losses and lifting efficiency}

Definitely, the kinematic factor (KF) is an important factor that affecting the carrot losses represents in the un-lifted roots and lifting efficiency. As mentioned the highest values of lifting efficiency and lowest values of losses were achieved at the optimum value of kinematic factor which was 3.57 , as shown in Fig. 7-a. The obtained results showed that the increase of belt speed from 1 to $2 \mathrm{~m} / \mathrm{sec}$., at forward speed $2 \mathrm{~km} / \mathrm{hr}$., as the KF reached the optimum value, the lifting efficiency tends to increase from 92.62 to $98.54 \%$ while the carrot root losses decrease from 0.89 to $0.18 \mathrm{Mg} /$ fad. However, the further increase in belt speed from 2 to $4 \mathrm{~m} / \mathrm{sec}$., means the $\mathrm{KF}$ is higher than the optimum value causing a clear decrease in lifting efficiency from 98.54 to $86.93 \%$ in addition to increasing the losses from 0.18 to $1.57 \mathrm{Mg} / \mathrm{fad}$. The lower values of $\mathrm{KF}$ than the optimum may decrease the lifting efficiency and increasing losses because the forward speed was higher than the belt speed which lead to increase the un-lifted roots. At lower higher of KF than the optimum means that the belt speed higher than the forward speed, which causes increasing in dislocations of foliage from the carrot root that led to increase the un-lifted roots and consequently decrease the lifting efficiency.

Fig. 7-b display that, increasing the belt tilt angle will lead to a rapid decrease in lifting efficiency and increase the losses due to dislocation of foliage that occurred during the lifting process during harvesting resulting in a corresponding increase in the un-lifted roots losses, especially at forward speeds higher than $2 \mathrm{~km} / \mathrm{hr}$. The obtained results showed that increasing in belt tilt angle from $30^{\circ}$ to $40^{\circ}$ at belt speed $2 \mathrm{~m} / \mathrm{sec}$., forward speed $2 \mathrm{~km} / \mathrm{hr}$., and rake angle $15^{\circ}$ led to increase the losses from 0.18 to $0.63 \mathrm{Mg} / \mathrm{fad}$., and then the lifting efficiency decreased from 98.54 to $94.74 \%$.

Fig. 7-c show that, the digging share rake angle doesn't affect any way the lifting efficiency or root losses due to the lifting efficiency and losses in this type of machine depends mainly on the forward speed, belt speed and belt tilt angle. Practically, the digging share working to make the cleavage and dismantling the soil section beneath the carrot root to facilitate the lifting process regardless to the rake angle value.

It is obvious that, the highest value of lifting efficiency of $98.84 \%$ and minimum root losses of $0.18 \mathrm{Mg} /$ fad., was achieved at forward speed $2 \mathrm{~km} / \mathrm{hr}$., belt speed of $2 \mathrm{~m} / \mathrm{sec}$., share rake angle of $15^{\circ}$ and belt tilt angle of $30^{\circ}$.

\section{Effect of some operational parameters on power and specific energy requirement}

Fig. 8-a-c show that, the specific energy consumption decreased by increasing the forward speed and the contrarily was occurred with the consumed power under all parameters of the experiment. This decrease can be attributed to the increase of the actual field capacity compared to the increase of the consumed power when the forward speed increased. Regarding the power and specific energy requirement, the increase of forward speed from 1 to $4 \mathrm{~km} / \mathrm{hr}$., at belt speed of 2 $\mathrm{m} / \mathrm{sec}$, share rake angle of $15^{\circ}$ and belt tilt angle of $30^{\circ}$, the required power increased from 9.38 to $14.49 \mathrm{~kW}$ and the specific energy decreased from 146.57 to $62.73 \mathrm{~kW} . \mathrm{hr}$./fad., as illustrated in Fig.8-a. The obtained results show that the $\mathrm{KF}$ affects greatly the required power and specific energy during the carrot harvesting operation. 


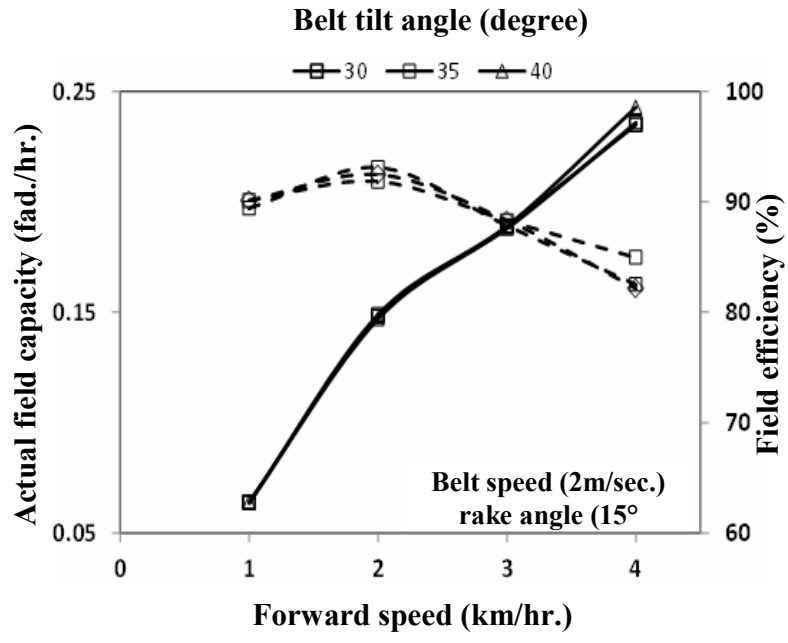

Fig. 6-c. Effect of belt tilt angle on the actual field capacity and field efficiency

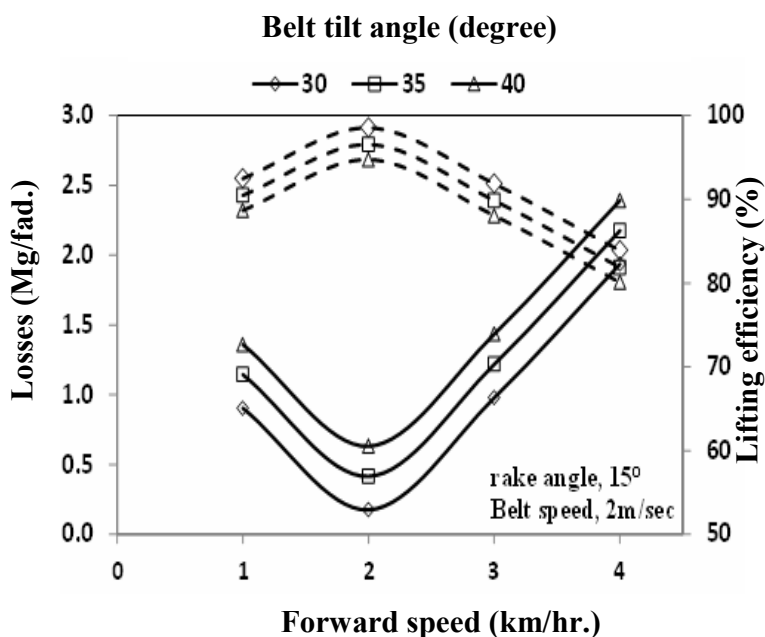

Fig. 7-b. Effect of tilt belt angle on losses and lifting efficiency

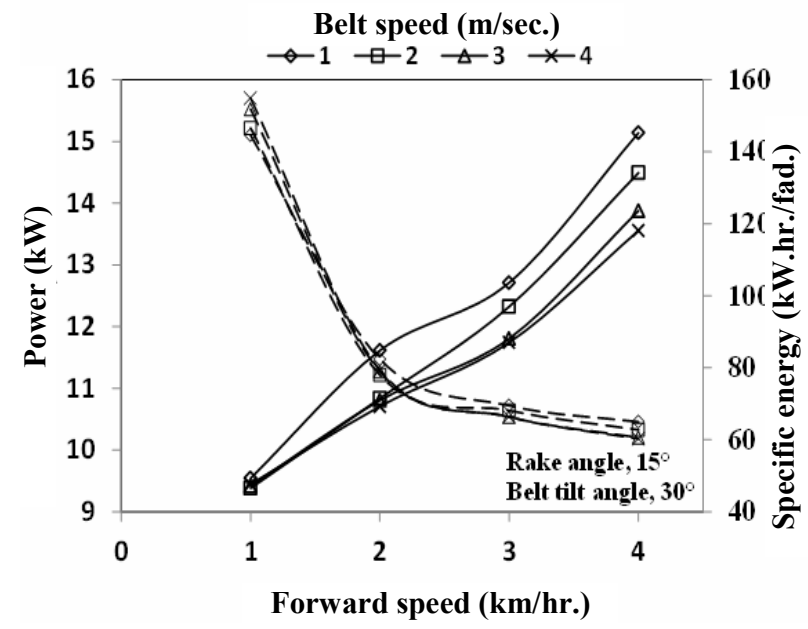

Fig. 8-a. Effect of forward speed and belt speed on power and specific energy

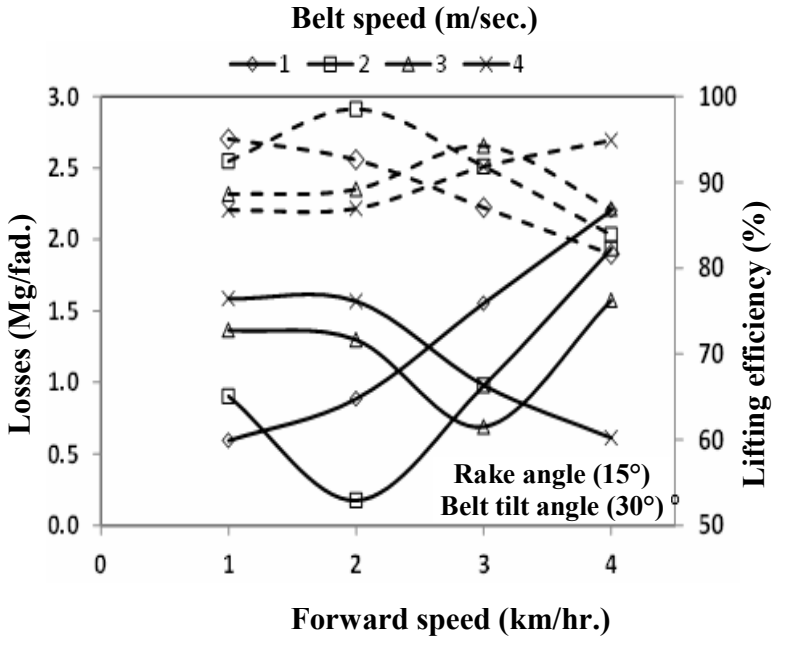

Fig. 7-a. Effect of forward speed and belt speed on losses and lifting efficiency

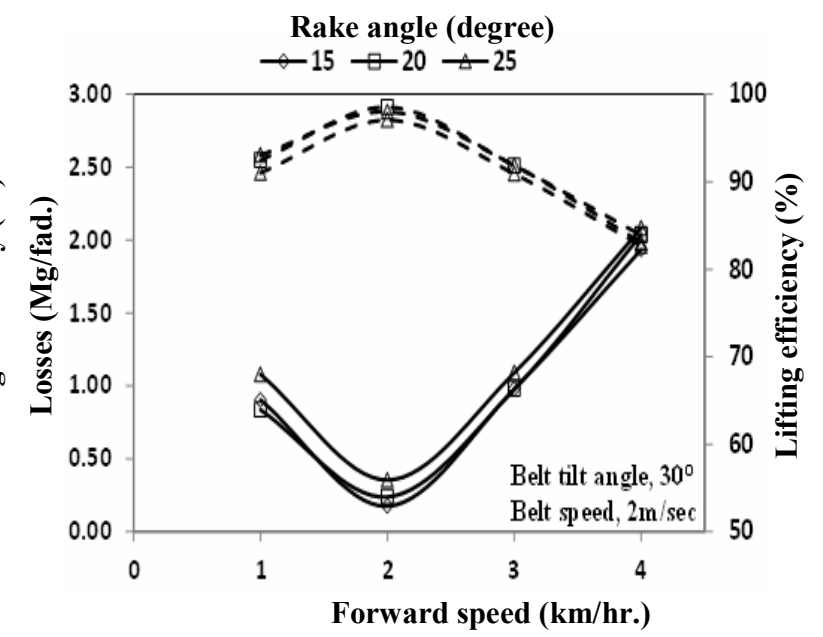

Fig. 7-c. Effect of rake angle on losses and lifting efficiency

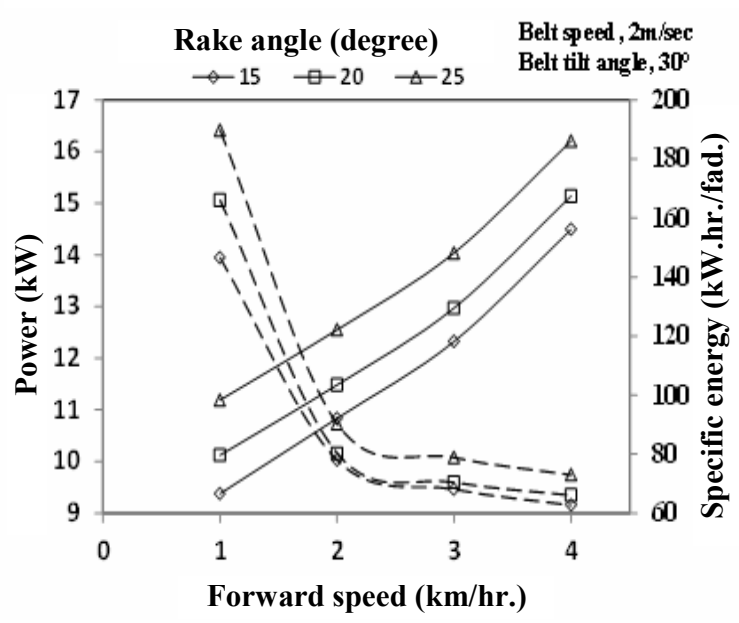

Fig. 8-b. Effect of rake angle on power and specific energy 


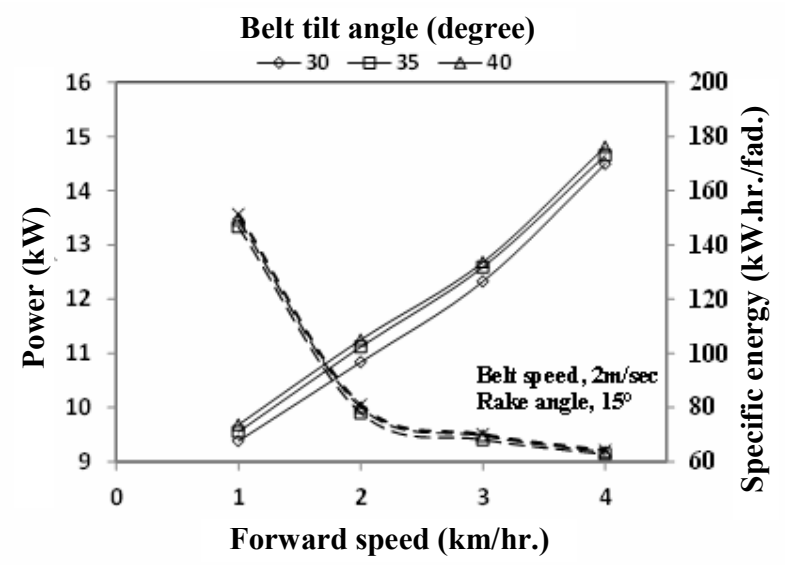

Fig. 8-c. Effect of belt tilt angle on power and specific energy

As mentioned, the optimum $\mathrm{KF}$ was estimated to be 3.57 , so the increase of KF more than the optimum value, the belt speed will be higher than forward speed, which made the lifting operation occur rapidly, hence there, is no noticeable change in both of required power and specific energy. However, the small value of KF means that the belt speed is lower than forward speed which gathering an excessive plants in the front of machine as severe block at the lifting pick-up point that leads to increase fuel consumption and consequently the required power and specific energy. The increase in belt speed from 1 to $2 \mathrm{~m} / \mathrm{sec}$, at forward speed of 2 $\mathrm{km} / \mathrm{hr}$., rake angle of $15^{\circ}$ and belt tilt angle of $30^{\circ}$ as the KF reached the optimum value of 3.57 , the required power and specific energy tend to decrease from 11.61 to $10.84 \mathrm{~kW}$ and from 82.36 to $77.96 \mathrm{~kW} . \mathrm{hr}$./fad., respectively. However, further increase in belt speed from 2 to $4 \mathrm{~m} / \mathrm{sec}$., the required power and specific energy almost tend to be stable.

Fig. 8-b display that, the increase of the share rake angle would increase the consumed power and specific energy due to increasing the soil resistance. The results showed that the increase of rake angle from $15^{\circ}$ to $25^{\circ}$ at forward speed 2 $\mathrm{km} / \mathrm{hr}$., led to increase the consumed power from 10.84 to $12.55 \mathrm{~kW}$ as well as specific power from 77.96 to $90.29 \mathrm{~kW} . \mathrm{hr} . / \mathrm{fad}$., at belt speed of $2 \mathrm{~m} / \mathrm{sec}$., and belt tilt angle of $30^{\circ}$. As general trend, the lowest values of required power and specific energy recorded at share rake angle $15^{\circ}$.
As seen in Fig. 8-c, the belt tilt angle has not clear influence on the required power and specific energy during the harvesting process. This because that the digging share not only make a cleavage and dismantling the soil section beneath the carrot root but also works to push the carrot roots up towards the soil surface and then the consumed power and energy for lifting did not affect greatly by the value of the belt tilt angle.

Generally, the optimum power and specific energy requirement were $10.48 \mathrm{~kW}$ and 77.96 $\mathrm{kW}$.hr./fad., was recorded at forward speed 2 $\mathrm{km} / \mathrm{hr}$., belt speed of $2 \mathrm{~m} / \mathrm{sec}$., share rake angle of $15^{\circ}$ and belt tilt angle of $30^{\circ}$.

\section{Effect of some operational parameters on total cost}

The total cost of carrot mechanical harvesting is mainly including the machine cost and manual collecting cost of losses represents in the unlifted roots, in other word the remained root in field.

Fig. 9-a show that, by increasing the belt speed from 1 to $2 \mathrm{~m} / \mathrm{sec}$., at forward speed of 2 $\mathrm{km} / \mathrm{hr}$., belt tilt angle of $30^{\circ}$ and share rake angle of $15^{\circ}$, the total cost of mechanical harvesting decreased slightly from 553.63 to 424.32 LE/fad. Nevertheless, the total cost increased from 424.32 to $638.75 \mathrm{LE} / \mathrm{fad}$., by increasing the belt speed from 2 to $4 \mathrm{~m} / \mathrm{sec}$., under the same mentioned conditions.

On one hand, the high value of KF than the optimum (3.57) can lead to increase the cost of 


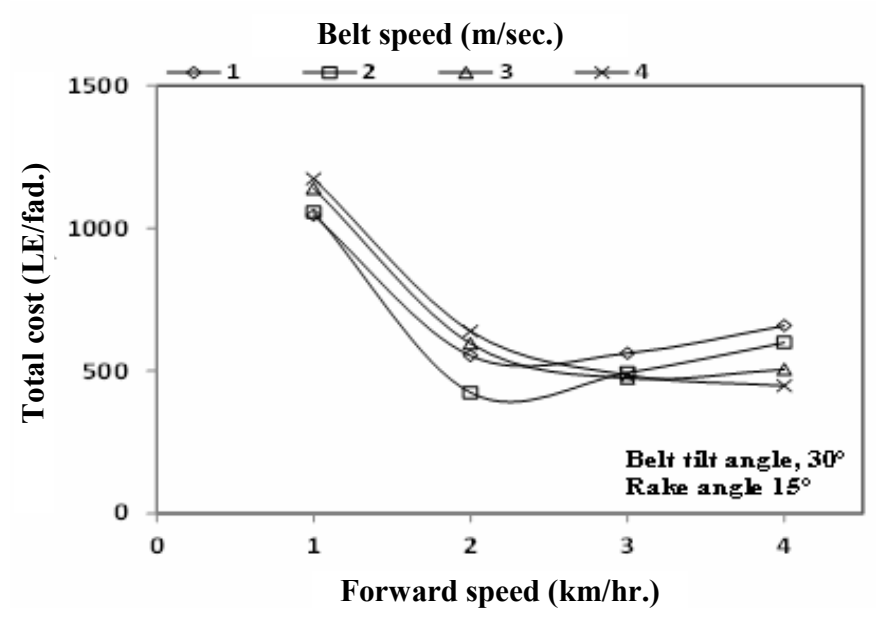

Fig. 9-a. Effect of forward speed and belt speed on total cost

collecting losses due to the dislocation that can be occurred by the increase of belt speed compared to the forward speed. On the other hand, the low values of KF than the optimum means a slow belt and forward speed that lead to increase the fuel consumption and consequently the power as well as the energy due to the high load caused by gathering an excessive plants at the picking-up point of the harvester. It is obvious that the machine adjustment at the optimum value of KF plays an important role in the reduction of harvesting cost.

Fig. 9-b display that, the increase of belt tilt angle from $30^{\circ}$ to $40^{\circ}$ using the optimum value of KF (forward speed of $2 \mathrm{~km} / \mathrm{hr}$ and belt speed of $2 \mathrm{~m} / \mathrm{sec}$.) under share rake angle $15^{\circ}$ led to increase the lowest values of total cost from 493.67 to $645.53 \mathrm{LE} /$ fad.

Fig. 9-c illustrate that increasing rake angle from $15^{\circ}$ to $25^{\circ}$ at forward speed of $2 \mathrm{~km} / \mathrm{hr}$., under belt speed value $2 \mathrm{~m} / \mathrm{sec}$, , and belt tilt angle $30^{\circ}$, the total cost increased from 424.32 to $450.09, \mathrm{LE} / \mathrm{fad}$.

Generally, the high total cost was recorded at share rake angle of $25^{\circ}$ and the lowest value was achieved at $15^{\circ}$ under the all parameters of the experiment. This attributed to the increase in share rake angle causes a clear increase in the operational cost of the machine due to the increase of fuel consumption. From the obtained results, it is recommended to operate the carrot harvester under forward speed of $2 \mathrm{~km} / \mathrm{hr}$., belt speed of $2 \mathrm{~m} / \mathrm{sec}$, belt tilt angle $30^{\circ}$ and share rake angle of $15^{\circ}$ to achieve the minimum value of harvesting total cost of $424.32 \mathrm{LE} / \mathrm{fad}$.

As seen in Fig. 9-d, the obtained results revealed that the total cost of manual harvesting method using nails was about 2202.37 LE/fad., while the lowest total cost of $424.32 \mathrm{LE} /$ fad., was achieved by using the carrot harvesting machine under the optimum operational parameters. Hence, it is obvious that using the prototype carrot-harvesting machine reduced the harvesting total cost by about $80.74 \%$ compared to the manual harvesting method.

\section{Conclusion}

According to the preliminary experiments, the prototype carrot harvester should be used under soil and foliage moisture content of 17.7 and $27.8 \%$, respectively at catch zone height of $15 \mathrm{~cm}$ and digging depth of $25 \mathrm{~cm}$. Regarding the field experiments, the operation of the carrot harvester using forward speed of $2 \mathrm{~km} / \mathrm{hr}$., belt speed of $2 \mathrm{~m} / \mathrm{sec}$., in other word the kinematic factor of 3.57 under belt tilt angle of $30^{\circ}, \mathrm{cm}$ and digging blade rake angle $15^{\circ}$ achieved the lowest losses of $0.18 \mathrm{Mg} /$ fad., highest lifting efficiency of $98.54 \%$, field efficiency of $92.50 \%$ at actual field capacity of $0.0148 \mathrm{fad} . / \mathrm{hr}$., with minimum total cost of $424.32 \mathrm{LE} / \mathrm{fad}$. Hence the using of the carrot harvester reduced the harvesting cost with about $80.74 \%$ compared to the manual harvesting method. 


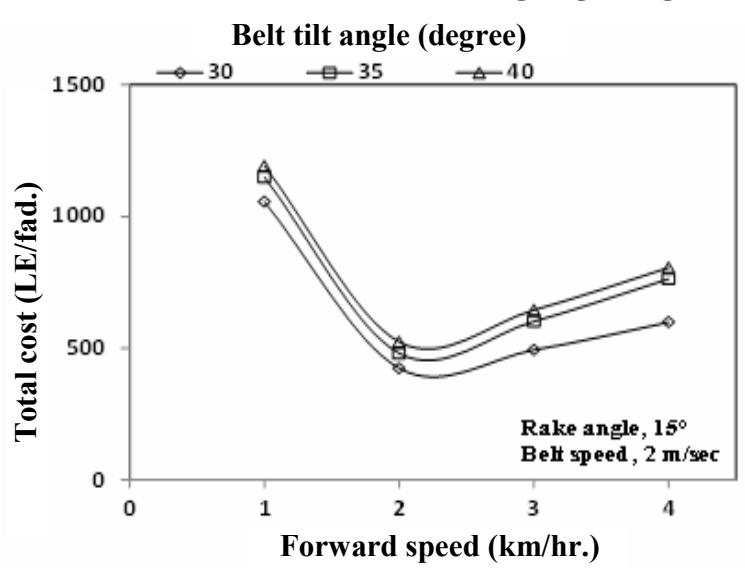

Fig. 9-b. Effect of belt tilt angle on total cost

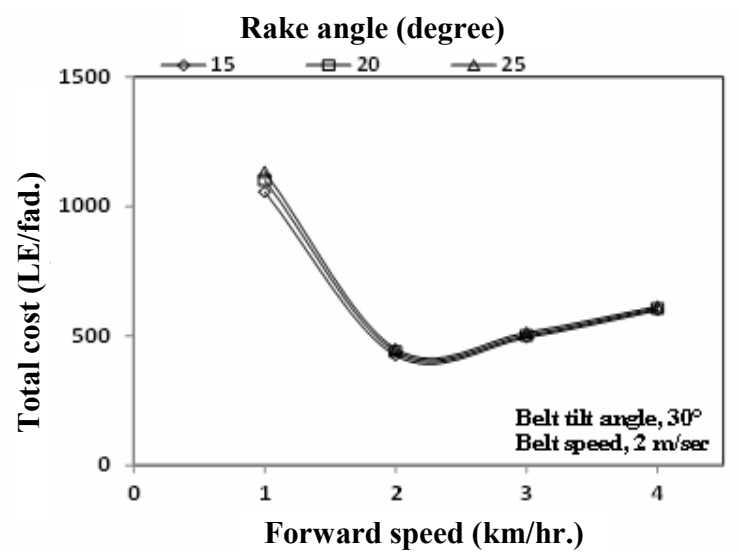

Fig. 9-c. Effect of rake angle on total cost

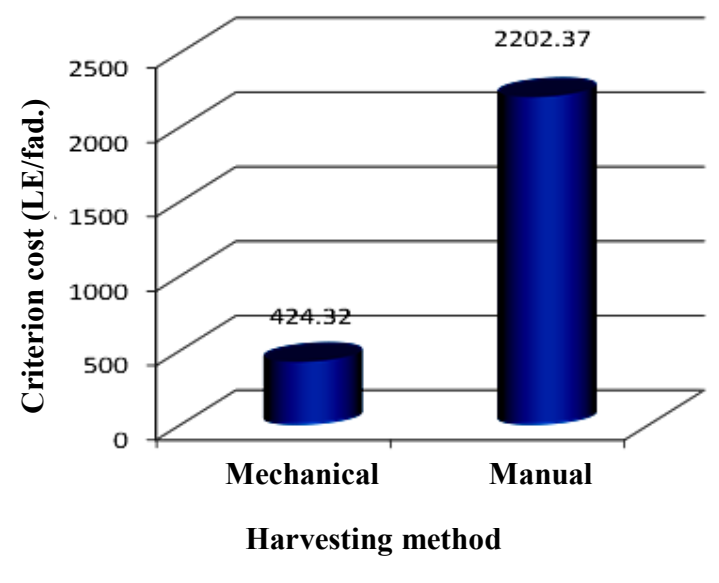

Fig. 9-d.Mechanical and manual harvesting total cost

\section{REFERENCES}

Amin, E.A., Z.E. Ismail, T.H. Elshabrawy and H.S. Faleih (2014). Influence of some factors affecting carrot harvesting. J. Soil Sci. and Agric. Eng., 5 (6): 911 - 92.

Awady, M.N., I. Yehia, M.T. Ebaid and E.M. Arif (2003). Development and theory of rice cleaner for reduced impurities and losses. Misr J. Ag. Eng., 20 (4) : 53-68.

FAO (2013) Production year book. The United Nations, http://faostat 3.fao.org/ browse/ Q/QA/E.
Hunt, R.D. (1983). Farm power and machinery management. $9^{\text {th }}$ Ed., Cushing-Malloy Inc., NY.

Moukhtar, S. (1997). Mechanization of carrot production. M.Sc. Thesis, Zagazig Univ., Egypt.

Shirwal, S., I. Mani and N.P.S. Sirohi (2014). Effect of design parameters on mechanical harvesting of carrot. Indian J. Agri. Eng., 2: 69-80.

Tawfik, M.A. and Y.S. Abdallah (2012). Fabricating a prototype of potato digger to suit small holdings. Misr J. Ag. Eng., 29 (2): $705-724$. 


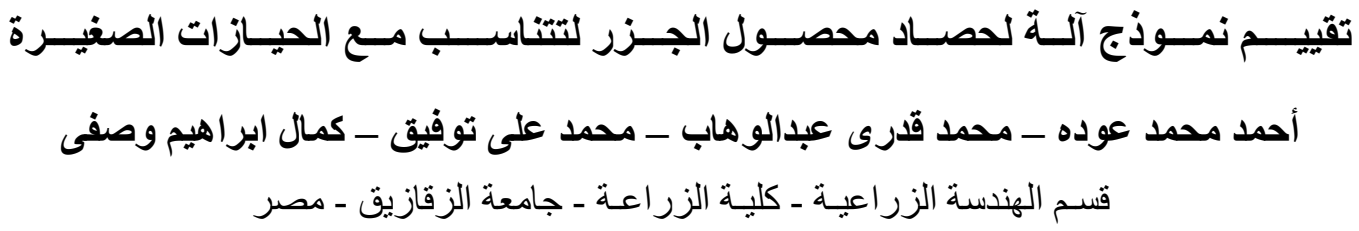

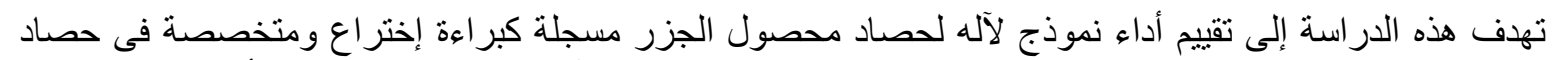

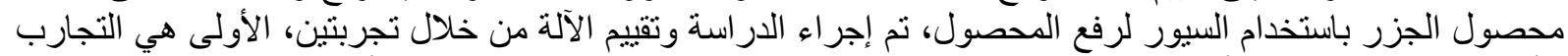

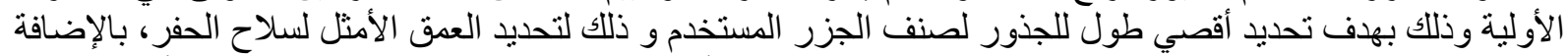

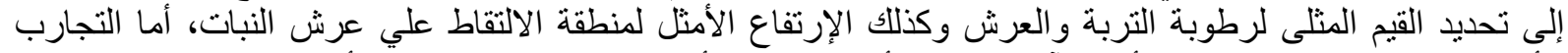

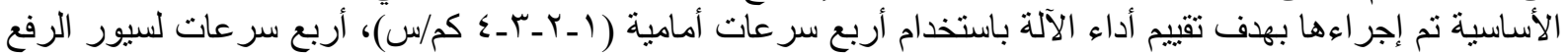

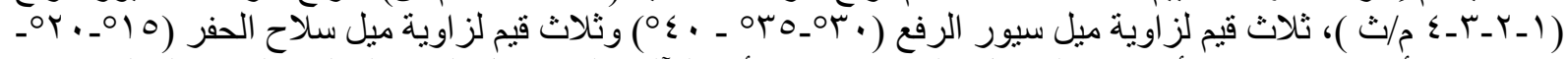

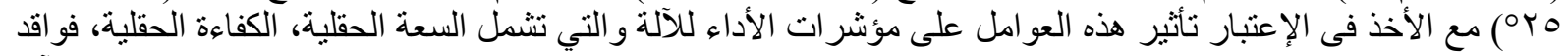

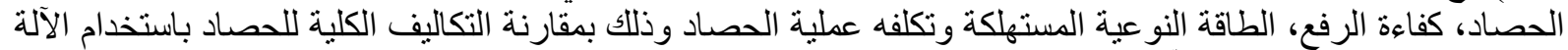

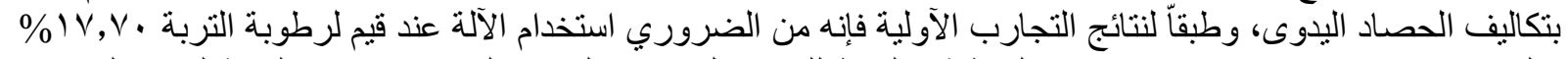

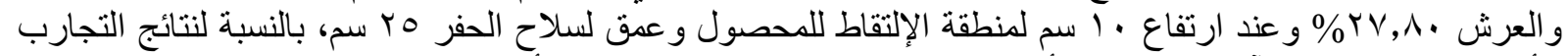

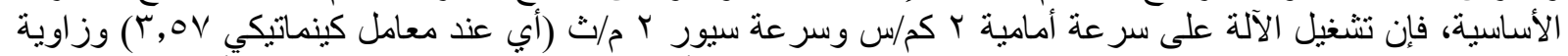

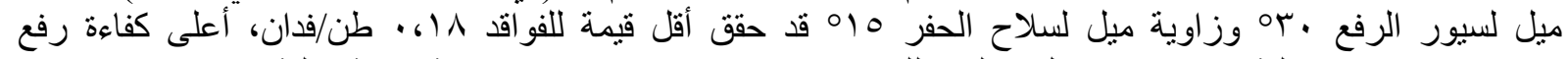

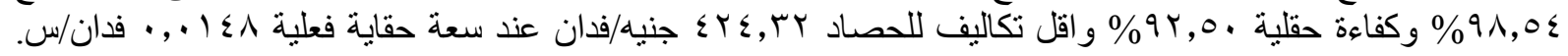

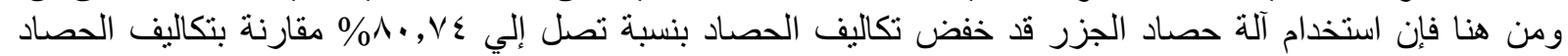
اليدوي.

أستاذ الهندسة الزر اعية المتفرغ - كلية الزر اعة ـ جامعة المنصورة.

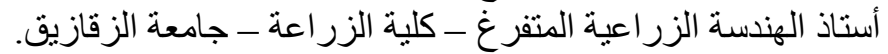

